\title{
SR Motor having Permanent Magnets and Windings in Stator Yoke
}

\author{
Y. Hasegawa, K. Nakamura, and O. Ichinokura \\ Graduate School of Engineering, Tohoku University, 6-6-05 Aoba, Aramaki, Aoba-ku, Sendai 980-8579, Japan
}

\begin{abstract}
The switched reluctance (SR) motor is low cost, extremely robust, and has a wide range of variable speeds. However, its power density is generally inferior in comparison with conventional permanent magnet (PM) motors. This paper presents a novel SR motor that has auxiliary windings and permanent magnets in the stator yoke. It operates similarly to a conventional SR motor in the motoring mode. On the contrary, it operates as a permanent magnet reluctance generator (PMRG) in the generating mode. The basic characteristics of the proposed SR apparatus operating as a motor and generator were calculated by using the finite element method (FEM), and compared with those of conventional reluctance machines.
\end{abstract}

Key words: Switched reluctance (SR) motor, auxiliary winding, permanent magnet

\section{固定子ヨークに永久磁石と巻線を有する SR モータ}

長谷川祐・中村健二・分倉理

東北大学 大学院工学研究科, 仙台市青葉区荒巻字青葉 6-6-05（９980-8579）

\section{1. はじめに}

スイッチトリラクタンス (SR) モータは, 安価で堅牢な可変速 モータとして期待されている1),2). 固定子，回転子はともに突極構 造を有し，巻線は固定子極のみに集中巻される，一方，回転子は 鉄心のみで構成され, 巻線や永久磁石は存在しない. したがって, $\mathrm{SR}$ モータは構造が極めて単純で堅牢であるため, 高速回転に適す る，熱や振動などに対する而性が高いなどの特長を有する.

SR モータは，これまでに掃除機や洗濯機など，家庭用電化製品 に実用化されてきたが，今後は電気自動車など，高出力密度が要 求される分野 の適用も期待される ${ }^{3)}$ ). . しかしながら，小型で大 出力が要求される分野において, 現在主流である永久磁石モ一タ と比較すると, SR モ一夕は出力密度が低いという技術課題がある. そこで本稿ではSR モータの出力向上を目的とし, 安価で入手し やすいフェライト磁石と, 巻線を補助的に利用した SR モータを提 案する. 提案機は, 従来の SR モータの固定子ヨークに補助巻線と 永久磁石を配置することで，鉄心の利用率を上げ，出力の向上を 図っている.また，発電機動作時には単純に補助巻線に直流電流 を流すだけで，電気出力を得ることができ，回転子位置角制御が 不要である. 3 次元有限要素法 (3D-FEM) の電磁界解析により, モータとしての性能について, 従来の SR モ一タと比較するととも に, 発電機動作時の特性についても評価を行ったので報告する.

\section{SR モータの基本構成と動作原理}

Fig. 1 に, SR モータの一般的な駆動回路である非対称ハーフブ リッジコンバータを示寸. 各相の巻線には，それぞれ 2 つのラ ンジスタと還流用ダイオードが接続されている，回転子位置角に 応じて, 各相のトランジスタを適切にスイッチングすることで, 直流電源からの電力を $\mathrm{SR}$ モ一タに供給して励磁を行う. また励磁 終了時には，巻線に蓄えられた磁気エネルギーが還流用ダイオー ドを介して電源に回生される.

ここで, モータの入力電力 $P_{\text {in }}$ は, 次式で与えられる.

$$
P_{\text {in }}=\frac{1}{T} \int_{0}^{T}\left(v_{\mathrm{a}} i_{\mathrm{a}}+v_{\mathrm{b}} i_{\mathrm{b}}+v_{\mathrm{c}} i_{\mathrm{c}}\right) \mathrm{d} t
$$

\section{は各相の巻線電流である.}

Fig. 2(a)に示すように, A 相の固定子極と回転子極が完全に対向 した位置を回転子位置角 $\theta=0^{\circ}$ とし, 時計回りの方向を回転の正 方向と定義すると, $\mathrm{A}$ 相巻線のインダクタンス $L_{\mathrm{a}}$ は, 同図(b)に示 すように $\theta=0^{\circ}$ で最大となり， $\theta= \pm 22.5^{\circ}$ で最小になる. ここで, $\mathrm{SR}$ モ一タの $\mathrm{A}$ 相を励磁した際に発生するトルク $\tau_{\mathrm{A}}$ は, 回転子位 置角 $\theta$ と磁気随伴エネルギー $W_{\mathrm{A}}{ }^{\prime}\left(i_{\mathrm{a}}, \theta\right)$ から次式で表すことができ る.

$$
\tau_{\mathrm{A}}=\frac{\partial W_{\mathrm{A}}{ }^{\prime}\left(i_{\mathrm{a}}, \theta\right)}{\partial \theta}
$$

ここで鉄心材料の磁気特性が線形であると仮定すると, 磁気随伴 エネルギー $W_{\mathrm{A}}{ }^{\prime}\left(i_{\mathrm{a}}, \theta\right)$ はインダクタンス $L_{\mathrm{a}}$ と相電流 $i_{\mathrm{a}}$ を用いて, 次 式で表される.

$$
W_{\mathrm{A}}^{\prime}=\frac{1}{2} L_{\mathrm{a}}(\theta) i_{\mathrm{a}}^{2}
$$

(2)，(3)式より $\mathrm{A}$ 相のトルク $\tau_{\mathrm{A}}$ は次式で与えられる.

$$
\tau_{\mathrm{A}}=\frac{1}{2} i_{\mathrm{a}}^{2} \frac{\mathrm{d} L_{\mathrm{a}}(\theta)}{\mathrm{d} \theta}
$$

したがって, 同図(b)に示すように, インダクタンス $L_{\mathrm{a}}$ の傾きが正 の領域で，A 相のトランジスタを ON し，励磁を行うことで，回 転方向と同一方向のトルクが得られる. 一方，インダクタンスの 傾きが負の領域で励磁を行うと, 回転方向とは逆の負トルクが発 生するため, SR モータの励磁タイミングは常に適切に制御する必 要がある. なお, 同図中の $\theta_{\mathrm{w}}$ は励磁幅, $\theta_{\mathrm{b}}$ は励磁開始角である.

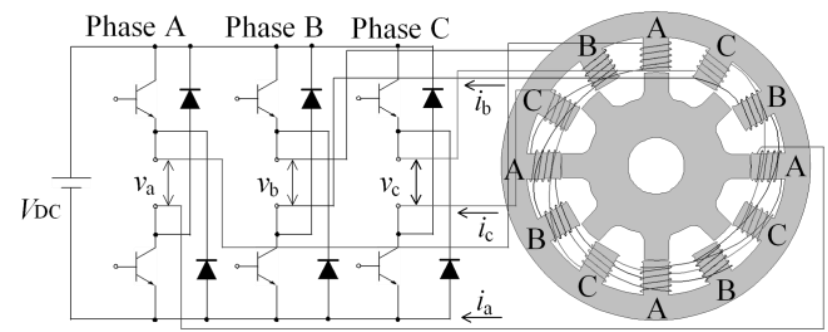

Fig. 1 Asymmetric half bridge converter.

上式において，T は周期， $v_{\mathrm{a}} ， v_{\mathrm{b}}, v_{\mathrm{c}}$ は各相の励磁電圧， $i_{\mathrm{a}}, i_{\mathrm{b}}, i_{\mathrm{c}}$ 


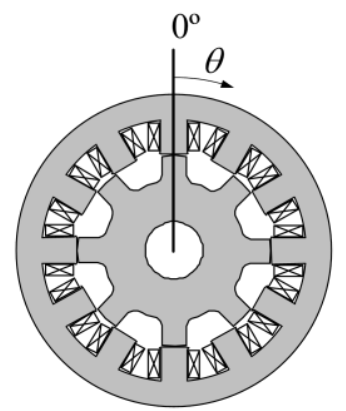

(a) Rotor position angle $\theta=0^{\circ}$

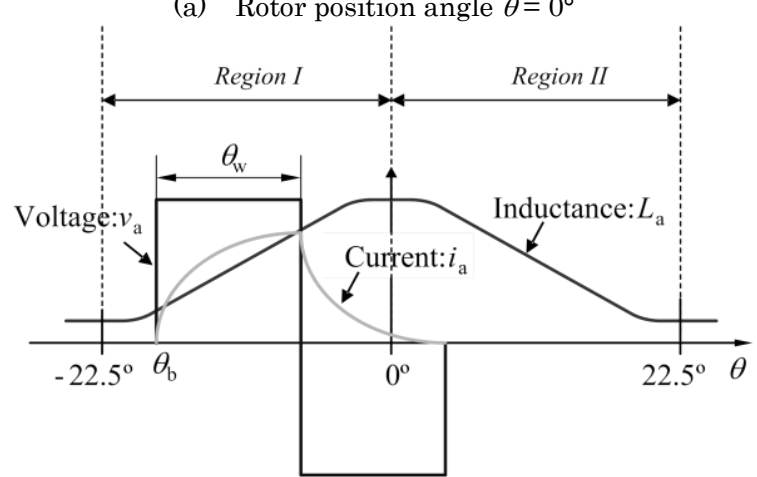

(b) Waveforms of $L_{\mathrm{a}}, v_{\mathrm{a}}$, and $i_{\mathrm{a}}$

Fig. 2 Schematic of waveforms of A-phase inductance $L_{\mathrm{a}}$, exciting voltage $v_{\mathrm{a}}$, and current $i_{\mathrm{a}}$.

\section{3. 提案機の基本構成と解析モデル}

\section{1 提案機の基本構成}

永久磁石の補助的な利用に関しては, 先行研究において, Fig. 3(a)に示すような, 固定子極間に磁石を挿入した SR モータが提案 されている 5). SR モータは, 一般にユニポーラ駆動されるため, 鉄心の動作点は Fig. 4(a)に示寸 $B-H$ 曲線の第 1 象限内に限定され るが, このSR モータでは, 磁石を用いて鉄心に逆方向のバイアス 磁界をかけるため，同図(b)に示寸ように，無励磁下において鉄心 の動作点が $B-H$ 曲線の第 3 象限までシフトする.これにより，鉄 心の動作領域が広がり，見かけ上の飽和磁束密度も $\left(B_{\mathrm{s}}+B_{\mathrm{m}}\right)$ と高 くなるため，トルクおよび出力が向上する. しかしながら，永久 磁石が固定子極の先端に配置されるため，巻線からの磁界の影響 を強く受ける. そのため, 保磁力の小さいフェライト磁石を用い た場合には，不可逆減磁が生じてしまう.

また同じく, 先行研究において, Fig. 3(b)に示すように永久磁石 を固定子ヨークに挿入した，永久磁石リラクタンスジェネレータ (PMRG) が提案されている6). PMRG は, 磁石が固定子ヨーク に配置されるため，電機子反作用磁界による減磁さ生じない，発 電機としての特性ではあるが，90\%以上の高効率を達成した報告 もある 7). しかしながら, Fig. 5(a)に示すように, PMRG を SR モータとして励磁した場合, 固定子巻線からの磁束の磁路に永久 磁石が存在することがわかる，才なわち，永久磁石の透磁率は空 気とほぼ等しいため，主磁路に極めて大きなギャップが存在する ことになり，特性は大幅に劣化する.

そこで本稿では，同図(b)のように一方の磁石を巻線で置き換え ることにより, 主磁路を確保し, 従来の SR モ一タと同様の駆動が 可能な SR モー夕を提案する.

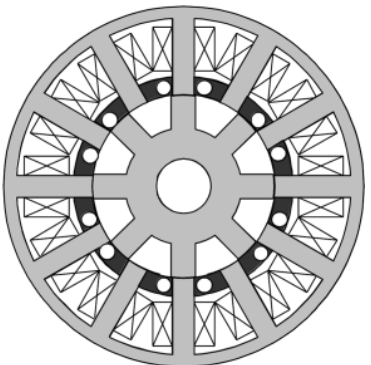

(a) SRM with PM

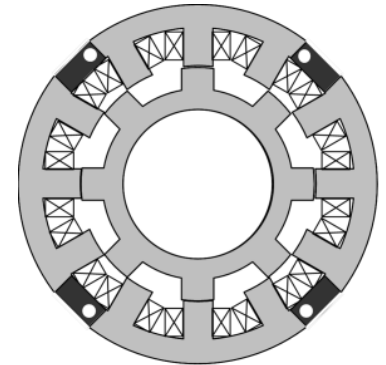

(b) PMRG
Fig. 3 Examples of SR motor with permanent magnet. (White point indicates the north-pole of PM.)

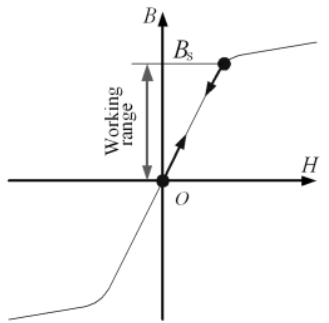

(a) Without magnets

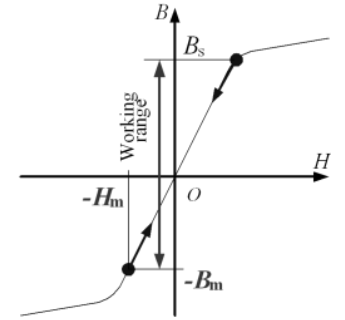

(b) With magnets
Fig. 4 Schematic of working range in stator pole.

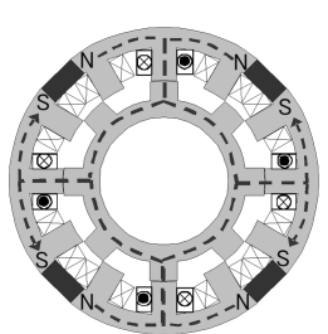

(a)PMRG

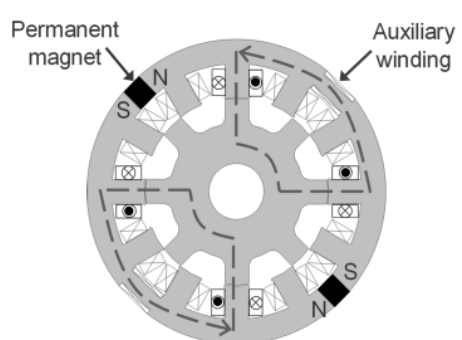

(b) Proposed motor
Fig. 5 Flux lines for SR motor with permanent magnets.

\section{2 提案機の諸元と解析モデル}

Fig. 6 に提案機の諸元を示寸. 本機は固定子 12 極，回転子 8 極 の 3 相機である. 一般的な SR モータと同様にユニポーラ駆動さ れ，各巻線による励磁の向きは，図中の矢印で示される．鉄心材 料は, 厚さ $0.35 \mathrm{~mm}$ の無方向性ケイ素鋼板（35A300）である. 磁石材料はフェライトであり, 保磁力は $325 \mathrm{kA} / \mathrm{m}$ である. 固定 子の外形はフェライト磁石の表面積を大きくするため，四角形と

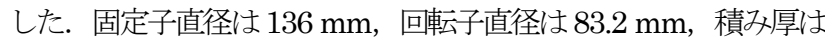
$40 \mathrm{~mm}$ ，ギャップ長は $0.2 \mathrm{~mm}$ である. ヨークの巻線部分の鉄心 幅については，固定子ヨークの最薄部幅 $(11.3 \mathrm{~mm})$ と等しく, 固定子極幅（10.8 mm）よりもわずかに広く設計した。

FEM による電磁界解析において, 提案機は軸方向の長さに対し て, 固定子直径が 3 倍以上であるため, 軸方向への漏れ磁束の影 響を考慮する必要がある．したがって，本稿では Fig. 7(a)に示す ような, 3 次元モデルを用いた. 提案機のモ一タとしての特性を評 価する際には，同図(b)に示寸非対称ハーフブリッジコンバータと 連成し，電源電圧は $60 \mathrm{~V}$ として解析を行った。 また，発電機とし ての特性を評価する際には，同図(c)の全波整流回路と連成し，補 助巻線には $8 \mathrm{~A}$ の直流電流を流して解析を行った. 


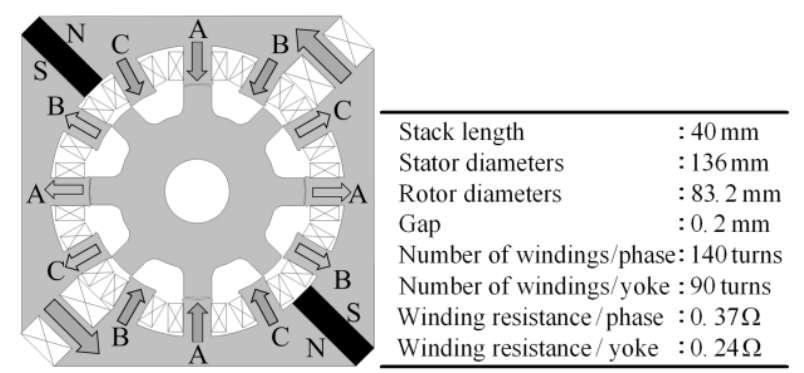

Fig. 6 Specifications for proposed motor.

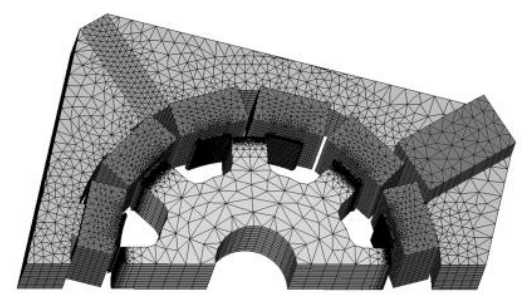

(a) Three-dimensional FEM model.
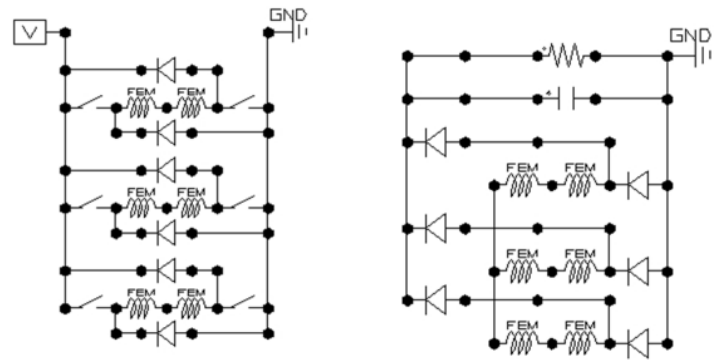

(b) Motor circuit model

(c) Generator circuit model

Fig. 7 Analytical model of proposed SR motor.

\section{4. 提案機の特性算定結果}

まず初めに，提案機のモータとしての特性を評価する. Fig. 8 に, 比較検討に用いた現有の 12/8SR モータを示寸8). 従来機の形 状・寸法，巻線などの仕様は，Fig. 6 の提案機とほぼ等しい.

Fig. 9 に電流密度対トルク特性を示す.この図を見ると, 提案機 と従来機はほぼ同じ特性を有することがわかる，これは提案機と 従来機の寸法がほぼ同じであるため, 提案機が永久磁石による逆 バイアスの効果を得られていないことが原因であると考えられる.

Fig. 10 に示寸ように, 提案機の固定子ヨークにおいては, 巻線 電流による磁束の向きと, 永久磁石による磁束の向きは反対であ るため, 従来機と比べて固定子ヨークの見かけ上の飽和磁束密度 は高くなる. したがって, 提案機は従来機よりもヨーク断面積を 小さくすることが可能であり, その結果, 固定子巻線の空面積を 大きくすることができる，そこで本稿では，初期設計の最薄部が 約 $11.3 \mathrm{~mm}$ の幅であるため, 機体の工作精度・強度を考えた上で 固定子ヨークの幅を一様に $6 \mathrm{~mm}$ 減らし, 同図に示すように, こ れにより広がった窓面積の分だけ，固定子巻線の巻数を 1 極当た り 35 回 から 54 回に増加させた. また, 巻数が増えた分だけ電源 電圧を $60 \mathrm{~V}$ から $92.5 \mathrm{~V}$ に高くした. これにより動作周波数，す なわち速度が一定に保たれる.

Fig. 11 に，寸法変更後の電流密度対トルク特性を示寸. この図 より，提案機と同様に寸法を変更した従来機と比較して，提案機 のトルクは $10 \mathrm{~A} / \mathrm{mm}^{2}$ において約10\%向上していることがわかる.
従来機では, $7 \mathrm{~A} / \mathrm{mm}^{2}$ 以降, 磁気飽和の影響によりトルクの増加 が鈍化しているが，提案機では磁石による逆バイアスの効果によ

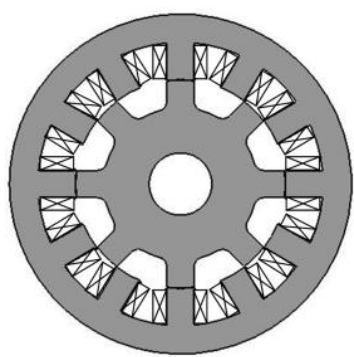

\begin{tabular}{ll}
\hline Stack length & $: 40 \mathrm{~mm}$ \\
Stator diameters & $: 136 \mathrm{~mm}$ \\
Rotor diameters & $: 83.2 \mathrm{~mm}$ \\
Gap & $: 0.2 \mathrm{~mm}$ \\
Number of windings/phase & $: 140$ turns \\
Winding resistance/phase & $: 0.37 \Omega$
\end{tabular}

Fig. 8 Specifications for conventional 12/8-pole SR motor.

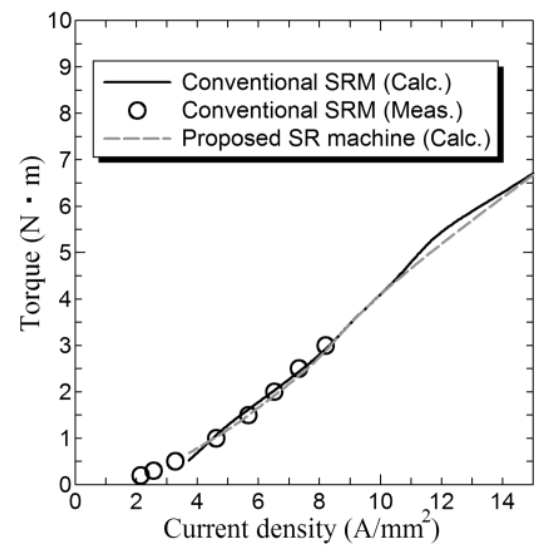

Fig. 9 Comparison of current density versus torque characteristics.

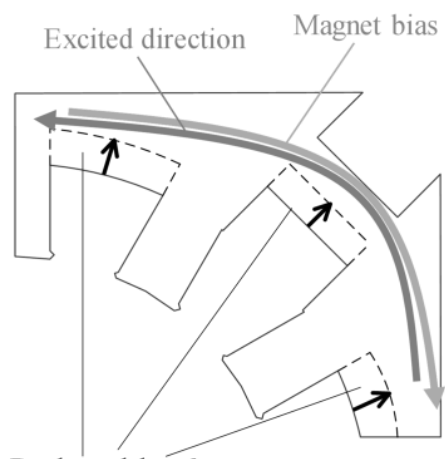

Reduced by $6 \mathrm{~mm}$

Fig. 10 Change in width of stator yoke.

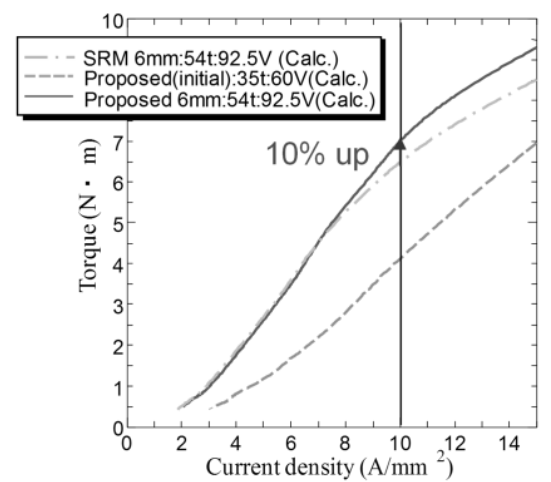

Fig. 11 Comparison of torque characteristics after change in dimensions. 


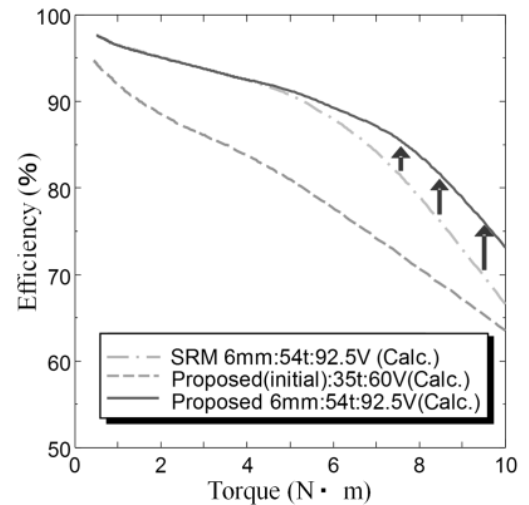

Fig. 12 Efficiency characteristics.

り，磁気飽和が緩和され，トルクが増加していることが了解され る. Fig. 12 に効率特性を示寸．損失として銅損のみを考慮した特 性であるが，銅損が支配的になる高負荷領域において，大きく特 性が改善されていることがわかる.

次いで, 提案機の発電機としての特性を評価する. Fig. 13(a)に, PMRGの磁束の流れを模式的に示す．永久磁石からの磁束は, 固 定子極と回転子極が対向した最も磁気抵抗が小さい磁路を通る. この状態から外力によって突極構造の回転子が回転させられると， これと対向する固定子極が周期的に切り替わるため, 磁束の流れ が変化し, その結果, 固定子巻線に電圧が誘起される.

同図(b)は，提案機の補助巻線に直流電流を流した場合の磁束の 流れである.この図を見ると，補助巻線に直流電流を流すことに より, PMRG と同様の磁束分布が得られることから，提案機は PMRG と同様の原理で発電することが推察される. また, Fig. 14 に提案機と PMRG の固定子巻線鎖交磁束を示す.このとき提案機 の補助巻線には $8 \mathrm{~A}$ の直流電流を流している. この図を見ると, 両者の鎖交磁束はほぼ等しいことが了解される.

Fig. 15 に，回転速度 $1000 \mathrm{rpm}$ 時の負荷特性を示す。この図よ り, 提案機と PMRG がほぼ同等の特性を有することが了解される.

\section{5. まとめ}

以上, 補助巻線と永久磁石を有する SR モ一夕を提案し, 従来機 との比較・検討を行った.

その結果，提案機は永久磁石による逆バイアス磁界を有効に利 用できるように，ヨーク断面積を小さくすることで, 従来の SR モ 一タに対して，約 10\%トルクが向上することが明らかになった。 また，高負荷領域において効率が向上した.

次いで提案機の補助巻線に直流電流を流寸ことで，従来の PMRG と同様の原理で発電が可能であることを示した. 発電特性 についても，PMRG とほぼ同等である.

今後は，実機による検証を行うとともに，モ一夕動作時にも補 助巻線を積極的に利用することで，さらなる性能の向上を目指寸 予定である. なお, 本研究の一部は科学研究費補助金若手研究(A) (22686028)，ならびに特別研究員奨励費（232218）の交付を受 け行った.

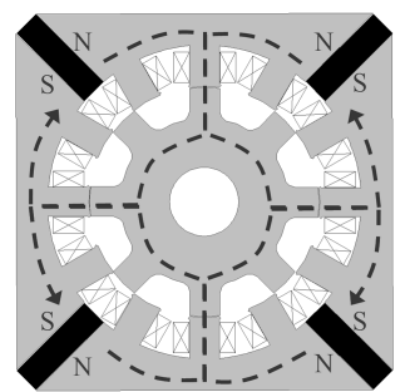

(a) PMRG

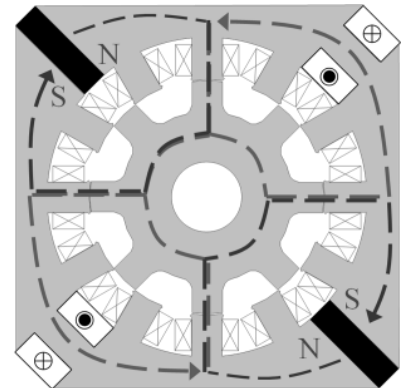

(b) Proposed motor
Fig. 13 Flux flows when proposed motor works as generator.

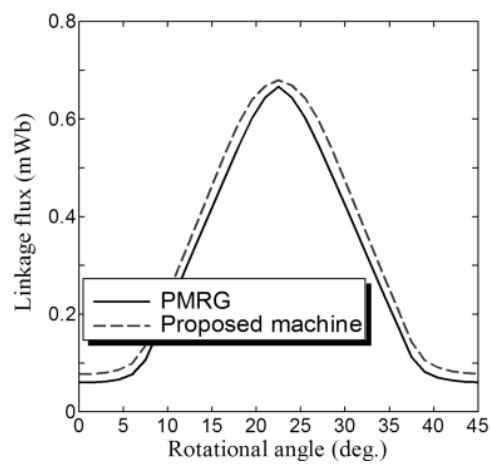

Fig. 14 Calculated waveforms of linkage fluxes.

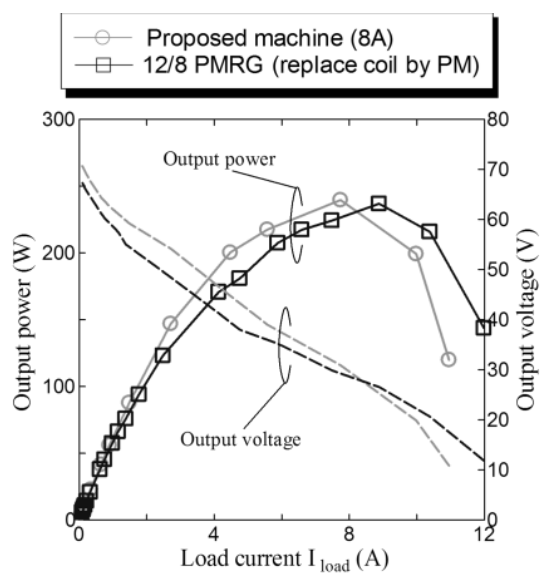

Fig. 15 Load characteristics of proposed motor working as generator at $1000 \mathrm{rpm}$.

\section{References}

1) N. Matsui and Y. Takeda, T. IEE Japan, 118-D, 685 (1998) (in Japanese).

2) R. C. Becerra, M. Ehsani, and T. J. E. Miller, IEEE Trans. Power Electron., 8, 257 (1993).

3) S. S. Ramamurthy and J. C. Balda, IEEE Trans. Ind. Applicat., 37, 1256 (2001).

4) H. Goto, Y. Suzuki, K. Nakamura, T. Watanabe, H. J. Guo and O. Ichinokura, Journal of Magnetism and Magnetic Materials, 290-291, 1338-1342 (2005).

5) K. Nakamura, K. Murota, and O. Ichinokura, J. Magn. Soc. Jpn., 31, 123 (2007) (in Japanese).

6) O. Ichinokura, J. Shida, K. Nakamura and T. Watanabe, $J$. Magn. Soc. Jpn., 29, 571 (2005) (in Japanese).

7) O. Ichinokura, T. Ono, K. Nakamura, and T. Watanabe, $J$. Magn. Soc. Jpn., 30, 408 (2006) (in Japanese).

8) Y. Hasegawa, K. Nakamura, O. Ichinokura, Journal of Physics: Conference Series, 266, 012067 (2011).

2011年 10月24日受理，2012年2月17日採録 